\title{
Commentary: Becoming a person centred practice
}

\author{
Farhan Amin general practitioner \\ Burnett Edgar Medical Centre, Barrow in Furness, LA14 3HY, UK
}

Providing patients with access to their medical records can improve their communication with clinicians and increase their understanding of their illness. It's therefore baffling that only $3 \%$ of people in the UK have online access to them. ${ }^{1}$ This should increase given NHS England's pledge to give patients full access to their medical records by 2018 .

The concerns Walker et al summarise about opening notes to patients ${ }^{2}$ were echoed in our practice two years ago, before we decided to offer patients full online access to their records. Concerns centred on the perceived administrative burden of implementation, having to change medical language, the security of online record systems, the confidentiality of third party data, patients getting worried about the results of tests and investigations, and whether people living in abusive relationships might be coerced into sharing access to their notes.

Despite these concerns we decided that our 4320 patient practice should aspire to become a leading person centred surgery. We saw providing online access to medical records, seamless information exchange, the promotion of patient partnership, and peer to peer support as central to achieving this. The move to open notes has not been easy. Until recently ${ }^{3}$ there was no national guidance and few pioneer practices to follow. Our initial priority was to develop a consent process, and we developed a specific form that we discuss with all patients who express an interest in online access to their medical record. We offer access during routine consultations and give patients who accept a named clinic member who will answer queries or concerns by email.

Our experience is limited. So far only around 80 patients have taken up online access (three quarters of those approached). We plan to continue enrolment at a steady pace over the next two years. Our observations suggest patients with access to their records take more control of their health. One person summarised it as, "No point in having access to medical records if I don't know what to do with it." We have had no complaints or concerns reported, and staff have noted correction of factual inaccuracies, reduced time spent answering phone calls for the results of investigations, fewer requests for review appointments, and more productive conversations when patients are seen.

Our second initiative to promote patient centred care has been to create Patient Memoirs (www.patientmemoirs.com), a local, web based, peer to peer support platform where people share experiences of living with illnesses and coping with its challenges. Again patient feedback has been positive.

Competing interests: I have read and understood BMJ policy on declaration of interests and declare that I set up Patient Memoirs as an independent venture.

Provenance and peer review: Commissioned; not externally peer reviewed.

Dinsdale P. Most people don't know they have the right to view medical records online. Guardian 2014 Nov 6. www.theguardian.com/healthcare-network/2014/nov/06/patientsright-to-view-gp-medical-records-online.

2 Walker J, Meltsner M, Delbanco T. US experience with doctors and patients sharing clinical notes. BMJ 2015;350:g7785.

3 Royal College of General Practitioners. Patient online practice toolkit. http://elearning rcgp.org.uk/course/view.php?id=180\&section=1. 